\title{
Design, Development and Testing of Traction Motor Speed Sensor used in Indian Railway Locomotive
}

\author{
Keerti Kurer \\ MTech, Student \\ Department of Electronics and \\ communication \\ KLE Dr. M. S. Sheshgiri \\ College of Engineering and \\ Technology
}

\author{
Nataraj A. Vijapur \\ Associate Professor \\ Department of Electronics and \\ Communication \\ KLE Dr. M. S. Sheshgiri \\ College of Engineering and \\ Technology
}

\author{
Prabhakar M. \\ Assistant Professor \\ Department of Electronics and \\ Communication \\ KLE Dr. M. S. Sheshgiri \\ College of Engineering and \\ Technology
}

\begin{abstract}
In Indian railway locomotive, the traction motor speed sensors are used to measure the speed of the traction motor and control the brakes applied on the machines. These play a vital role in the train state control, stability of the motor and monitoring of the systems. In the past, it seen that there are no test benches reported for the traction motor speed sensors. It is also seen that there are speed control methods implemented using different controllers such as FPGA, MATLAB on DSP kits. Henceforth this work can be improvised by creating a test bench for the traction motor speed sensor. The creation of test benches, controlling the speed of the traction motor and performance of the traction motor speed sensors is executed on railway locomotives which is shown in this paper. This work is done using controller and hall effect sensor as feedback circuit given to the controller. So, it is seen that there can be an ease of conducting an experiment for traction motor speed sensor using main controller board.
\end{abstract}

\section{Keywords}

Hall effect sensor, Traction motor speed senor, speed control, Brushless DC motor.

\section{INTRODUCTION}

Indian Railways is the most busiest and largest rail network in the world. Rail transport comes under the Ministry of Railways[1]. Rail transport is a method of transportation for travelers and products on wheeled vehicles running on rails. Railroad transportation has the attributes of all-inclusive statement, high speed, huge limit, low energy utilization, low contamination and high security, which has been turning into the most vital one of a wide assortment of transportation ways. Rail travel has transformed into a large utilized strategies for transportation inferable from its immense utmost, quick, low energy use and other remarkable characteristics. The quick change in advance rail travel has extended the amount of sensors associated on trains. These adopt a necessary part in train state control and observing. As a sort of identifier, sensors can feel assessed information and change over it into electrical signs as demonstrated by particular standards. This accepts a crucial part in ensuring the execution, prosperity, and learning of rail travel plan systems.
The brushless DC system is just permitted to operate at a low duty cycle or a high duty cycle. A speed control method of brushless DC motor using Hall effect sensor[2]. Speed regulation is accomplished by rotating between low duty cycle and high duty cycle, which makes the concept of the controller with the simple straight forward design and execution. The permanent magnet synchronous motor(PMSM), also known as sinusoidal BLDC motor using hall effect sensors[3] are used to control the speed of the motor. The speed control in a brushless DC motor includes changing the connected voltage across the engine stages. This should be possible using a sensored strategy because of pulse width modulation(PWM), or hysteresis control. A control algorithm is simple and improves the performance of the BLDC motor pulse width modulation speed controllers using field programmable gate arrays[4]. The speed control in a brushless DC motor includes changing the connected voltage across the engine stages. This should be possible using a sensored strategy because of pulse width modulation(PWM), or hysteresis control. The rotor position data from the hall effect sensors, a trapezoidal drive method is applied to the brushless DC motor[5]. Brushless DC engines require less support because of the end of the mechanical commutators and brushes. Brushless DC engines have speedier unique reaction because of their low idleness(lasting magnet) rotor contrasted with enlistment engines.

\section{PROPOSED WORK}

\subsection{Block Diagram}

From the block diagram described below, explains the working of the system. The main controller provides the pulse width modulation(PWM) signals to the motor. These pulse signals cannot be directly sent to the motor due to the changes in the high to low or low to high duty cycles/voltages continuously. So the motor drive circuit is used to check the duty cycles of the pulse signals and then drive the traction motor with the given speed. The controller provides the assigned pulse width modulation voltage signals to the motor which is passed through the motor drive circuit. This motor drive circuit converts the duty cycles as required by the traction motor speed sensor. The speed of the motor is set by assuming some values. 


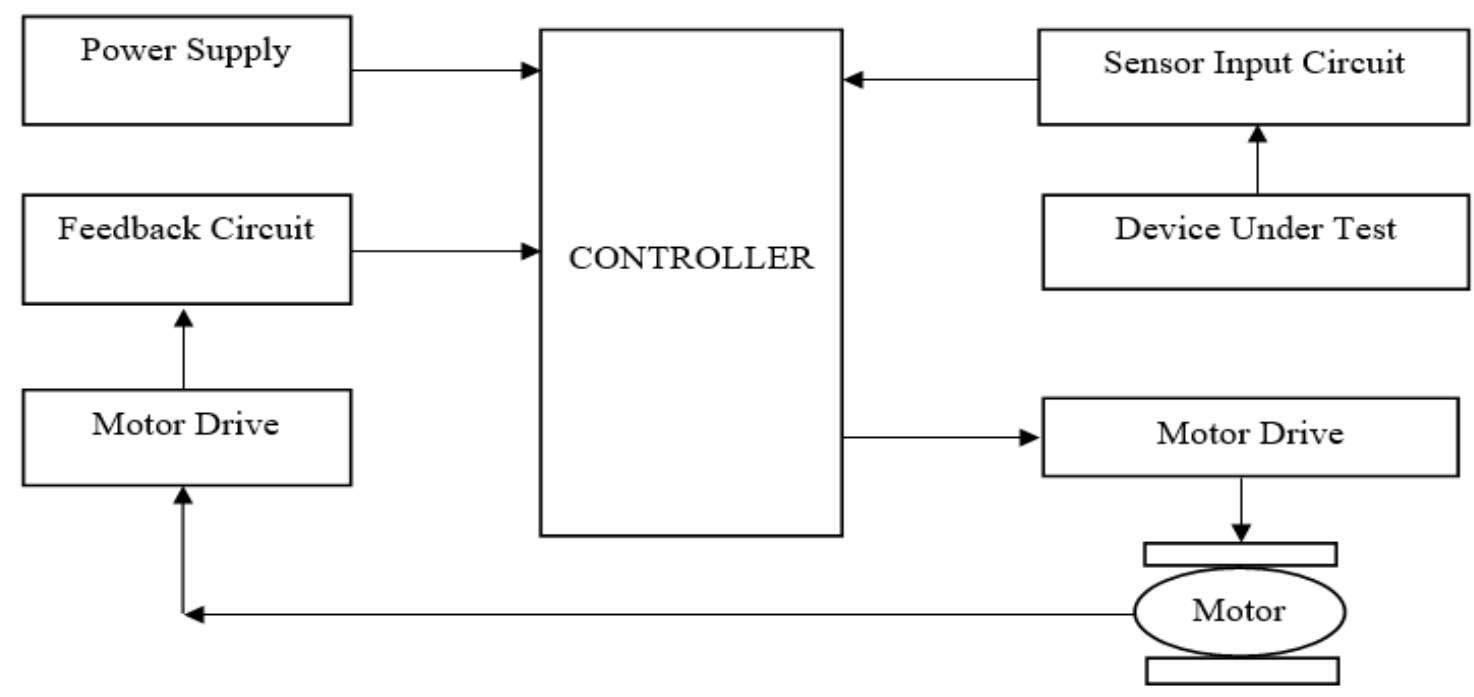

Figure-1: Working block diagram of the system

Once the motor starts to rotate, the speed of the motor is sensed and the sensed values are recorded and assigned to the controller as feedback The speed of the motor is adjusted until the exact speed is observed from the sensor. Once the exact speed is observed from the sensor, the device under test(DUT) that is traction motor speed sensor values are recorded. From external the readings are recorded through the tachometer. The traction motor[6] speed sensor and the tachometer readings are observed and a difference is taken. Once the difference are nearby to the tolerance of the device under test set at the beginning then the device is said to be pass or else the device is fail. Equations to calculate the speed of the motor and comparison to see the control over the motor speed.

Speed of the motor $=60 * 1000 /(2 * 32 *$ pulse value $)$

Device tolerance $=$ speed of the motor - tachometer reading

\subsection{Algorithm}

The algorithm gives the step by step procedure to execute the work which is to be done. The step by step explanation for this as follows:

1. Start and initialize the input and output variables which are necessary for the further storing of data in it.

2. Now set the values for the stepper motor speed in rpm and also set the device under test tolerance.

3. The feedback circuit gives a speed output which is taken from the stepper motor and checked for the exact speed required.

4. Calculate for the required stepper motor speed by comparing with the set value.

5. Once the exact value is taken from the speed sensor, the external device comes into consideration that is device under test. This device under test takes the speed value from the stepper motor through tachometer.

6. The device under test value is compared with the stepper motor rpm sensor reading.

7. The difference between the device under test reading and the stepper motor rpm sensor reading is compared with the device under test tolerance.

8. The result of the comparison is displayed as DUT pass or DUT fail.

\subsection{Implemeentation}

The implementation of the work is carried out, which shows the matching of the speeds recorded from different ways. Once the speed values match, the Device Under Test(DUT) is said as pass or fail. At first, the work is explained as:

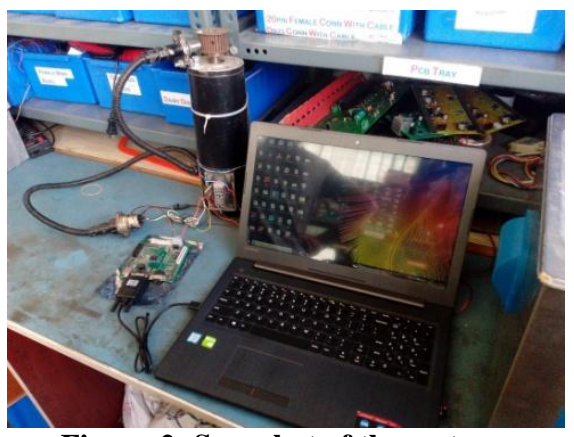

Figure-2: Snapshot of the system.

The connections from the above snapshot is explained as follows: The controller is connected to the laptop through the USB cable, which supplies power to the board. Controller is not directly connected to the motor because there is voltage difference from the output of the controller and the input of the traction motor. So to regulate the supply voltage to the traction motor, there is a motor drive circuit which controls the flow of the current and voltage. Then the traction motor takes the assigned rpm value from the controller and starts to rotate.

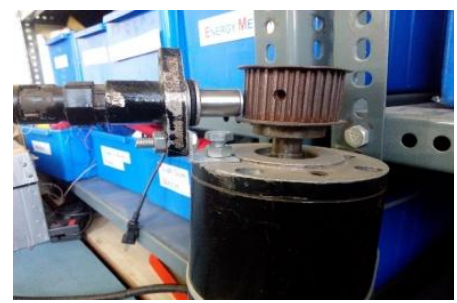

Figure-3: Connection to the motor and the speed sensor

The above figure depicts about the connection with traction motor speed sensor[7] and the $24 \mathrm{~V}$ brushless DC motor. This connection illustrates about speed of the motor which is assigned at the beginning of the procedure and the values are 
acquired from the traction motor speed sensor and tachometer. This acquired values from the traction motor speed sensor is recorded and sent to the controller through the feedback circuit.

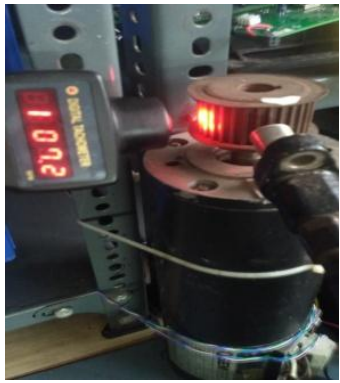

Figure-4: Snapshot of working setup

The matching of the readings from the tachometer and the device under test that is traction motor speed sensor is shown in the snapshot. Here the device under test senses the speed of the motor. Tachometer[8] is used to take the external readings of the motor. The traction motor speed sensor and tachometer readings are compared and a difference is taken. This difference is again compared with the tolerance of the device under test. Once the comparison is done, it is noticed that, the device under test is pass or fail.

\section{EXPERIMENTAL RESULTS}

The results of the implemented work is taken from the output of the sensor and compared with the input value set at the beginning. The output tolerance is also compared with the input tolerance and once the correct readings are taken, the remark is given as pass or fail.

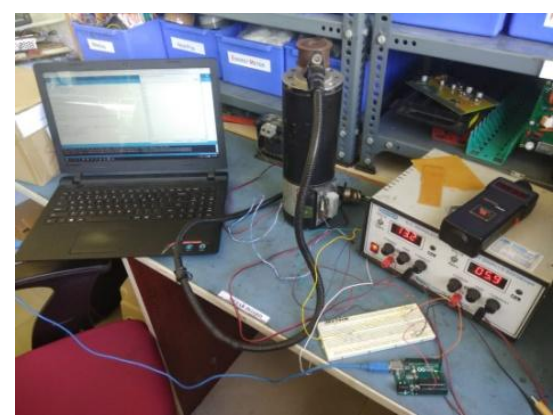

Figure-5: Final setup of the work

Table-1: First testing result

\begin{tabular}{|l|l|l|}
\hline $\begin{array}{l}\text { Standard output } \\
\text { value(volt) }\end{array}$ & $\begin{array}{l}\text { Output voltage(volt) } \\
\text { Tolerance(volt) }\end{array}$ & Remarks \\
\hline+5 & 0 & Fail \\
\hline+15 & 14.43 & Fail \\
\hline-15 & 0 & Fail \\
\hline $\begin{array}{l}\text { Sensor voltage } \\
>1.5\end{array}$ & $600 \mathrm{~m}$ & Fail \\
\hline Frequency-1KHz & $0 \mathrm{kHz}$ & Fail \\
\hline
\end{tabular}

There is much difference in the standard output value and the normal output value got after testing. Due to this difference the remarks here got is fail.
Table-2: Second testing result

\begin{tabular}{|l|l|l|}
\hline $\begin{array}{l}\text { Standard output } \\
\text { value(volt) }\end{array}$ & $\begin{array}{l}\text { Output voltage(volt) } \\
\text { Tolerance(volt) }\end{array}$ & Remarks \\
\hline+5 & 4.96 & Pass \\
\hline+15 & 14.92 & Pass \\
\hline-15 & -15.1 & Pass \\
\hline $\begin{array}{l}\text { Sensor voltage } \\
>1.5\end{array}$ & 1.6 & Pass \\
\hline $\begin{array}{l}\text { Frequency- } \\
1 \mathrm{KHz}\end{array}$ & $1 \mathrm{kHz}$ & Pass \\
\hline
\end{tabular}

There is no much difference found in the standard output and the normal output value recorded after testing. Now the device is considered as pass.

Table-3: Speed set at beginning and the output

\begin{tabular}{|l|l|l|}
\hline $\begin{array}{l}\text { Sl. } \\
\text { No }\end{array}$ & Input speed $(\mathrm{kmph})$ & Output speed (kmph) \\
\hline 1. & 10 & 9 \\
\hline 2. & 20 & 20 \\
\hline 3. & 40 & 39 \\
\hline 4. & 60 & 60 \\
\hline 5. & 100 & 100 \\
\hline 6. & 120 & 119 \\
\hline
\end{tabular}

The input speed is set according to the required values. Once the output speed is near to the input speed it is said that the device is pass or else it is said that it is fail.

\section{CONCLUSION AND FUTURE SCOPE}

This paper has proposed a new strategy for creation of a test bench for traction motor speed sensor used in railway locomotives and also controlling of speed in traction motors. A complete system used for creation of test bench includes the hardware and software components which are designed and implemented using a controller. Implementation of the test bench is done through the pulse signals created from the controller and sent to the traction motor through a motor drive circuit. Once the motor starts to rotate, the speed is sensed through the sensors and tachometer. Once the readings match the given input speed and the output speed, the system is indicated as pass or fail. By this it is seen that, the performance of the hardware output received is matching with the given input and successfully completed with effective performance and stable speed of the motor. Hence in future, work it can be improvised to create a test bench for traction motor speed sensor to get efficient performance and cost effective products for traction motors. This makes the motor to rotate according to the given vale and recorded from the output take from the sensor and the tachometer.

\section{ACKNOWLEDEGMENT}

I take this opportunity to thank my college KLE's. Dr.M.S.Sheshgiri college of Engineering \& Technology. I would like to extend my sincere thanks to Mr. Santosh Naganur; the co-founder and director of the company Think Circuit Technologies pvt ltd, Bangalore, without who's support and concern this work would not have been completed. 


\section{REFERENCES}

[1] https://en.wikipedia.org/wiki/Indian_Railways, about Indian railways introduction.

[2] Han-Chen WU, Min-Yi Wen and Ching-Chang Wong, "Speed Control of BLDC Motor Using Hall Effect Sensors Based on DSP," International Conference of System Science and Engineering(ICSSE), National Nan Chi University, Taiwan, July 7-9, 2016.

[3] Hrishikesh Mehta, Vrunda Joshi and Ujjwala Thakar, "Speed Control of PMSM with Hall Sensors Using DSP TMS320F2812," in Proc. 2015 The Eighth International Conference on Power Electronics and Drive System(PEDS), Australia, 2015, pp 295-300.Fröhlich, B. and Plate, J. 2000. The cubic mouse: a new device for three-dimensional input. In Proceedings of the SIGCHI Conference on Human Factors in Computing Systems.
[4] A. Tashakori, M. Hassanudeen and M. Ektesabi, "FPGA Based Controller Drive of BLDC Motor Using Digital PWM Technique," IEEE PEDS, Sydney, Australia, 9-12 June 2015, pp 658-662.

[5] B. Akin and M. Bhardwaj, "Trapezoidal Control of BLDC Motors Using Hall Effect Sensors," C2000 Systems and Applications Team, Texas Instrument.

[6] http://www.slideshare.net/RajneehBudania/tractionmotor, about traction motors and locomotives

[7] http://www.schrieverschulz.de/pdf/applik_bahnsensoren-e.pdf, about the traction motor speed sensor.

[8] https://en.wikipedia.org/wiki/Tachometer, Wikipedia about tachometer. 